\title{
Vocational Pedagogies: the Science of Teaching or the Teaching of Science?
}

\author{
Janet Hobley \\ Correspondence: Janet Hobley, School of Education Harcourt Hill Oxford OX29AT, UK
}

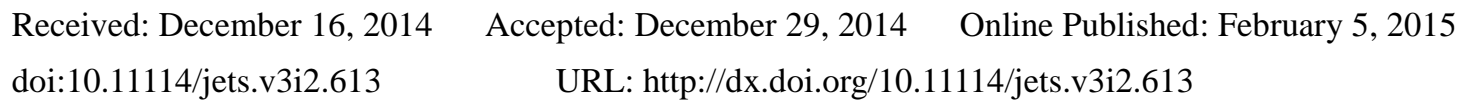

\begin{abstract}
:
This paper draws on recent reports and articles concerning vocational education and training which in 2014 aim to offer a theoretical underpinning for vocational pedagogy and one that promotes a greater understanding of how the 'practical knowledge' within vocational education and training can be developed through a consideration of different pedagogic practices. What these reports fail to do however is to address a consideration of the 'theoretical knowledge' within vocational areas of study currently on offer. This article, therefore seeks to provide an alternative view of vocational pedagogy that arises from a practitioner perspective of teaching science to vocational 'subjects' for a number of years. Hence it is an attempt to reframe the arguments for vocational pedagogy into a consideration of the teaching of 'science' within vocational education rather than an analysis of the newly defined concept of vocational pedagogy which implies that teaching vocational subjects is an art in itself.
\end{abstract}

Keywords: pedagogy, vocational education and training, vocational pedagogy, recontextualisation, vertical knowledge

\section{Introduction}

Currently in vogue, the notion of vocational pedagogy is in 2014, a recognised term for what may have been called Vocational Education and Training (VET) in the past. This term and meaning of vocational education and training have been 'contested' by many over a number of years, (Pring 1995, Moodie, 2006, Hodgson and Spours 2004, Hager, 2008, Polesel, 2001) with varying and alternative perceptions of the role of knowledge, qualifications and the policy initiatives of VET. Moodie (2002) for example attempted to theorise about the distinctiveness of vocational education and training by using four general characteristics, the epistemological, teleological, hierarchical and pragmatic in order to define the term. He concluded that vocational education and training is the "development and application of knowledge and skills for middle level occupations needed by society from time to time" (pg. 260). Hodgson and Spours (2004) on the other hand argue that vocational education and training in the UK contains a "fundamental paradox" (pg. 222) with tensions between employers and government as to its ownership and function. It can be argued that these differing definitions of what constitutes vocational education has led to some complexity and ambiguity in curriculum design and qualifications that do not always address the differing contexts of vocational subjects. Whilst Moodie does address the concept of epistemology he is still vague as to what exactly the knowledge within vocational education actually is. This article therefore attempts to bring this complexity and ambiguity up to date with an alternative view of what constitutes vocational pedagogy in 2014 through a consideration of the 'science knowledge' that lies within vocational education.

The teaching of vocational subjects has been a focus of government intervention since the Wolf Report (2011) raised questions about the nature and parity of vocational education. We now have publications from the Commission on Adult Vocational Teaching and Learning (CAVTL, 2013) as well as a Theory of Vocational Pedagogy (Lucas et al, 2012) both of which aim to develop a 'theoretical underpinning' of the teaching of vocational subjects. However it can be argued that both documents, whilst laudable in terms of raising the notion of vocational pedagogy, appear to miss out a core aspect of vocational subjects. The documents use the term 'pedagogy as the science of teaching' (Lucas et al, 2012, pg. 14) and it is this definition that appears to miss out what this author considers to be a key feature of vocational subjects, that within vocational subjects there is a large amount of the 'teaching of science'. Lucas et al in spite of their aim to develop a 'theoretical underpinning for vocational pedagogy' fail to fully explore the notion of the theoretical knowledge underpinning vocational subjects. CAVTL (2013) does acknowledge the "theoretical knowledge from the underpinning disciplines (for example, maths, psychology, human sciences, economics)" (pg.15) within vocational pedagogy but does no more, rather it uses terms such as "two way street" and "a clear line to work" (pg. 4) as being the 
key aspects of their findings. Bathmaker (2013), on the other hand, raises important questions about the 'knowledge' within vocational subjects and qualifications and concludes that there is a "complicated and unstable state of knowledge in vocational education qualifications" (pg.2) Her paper argues that the emphasis of VET in the past has been on the 'skill' involved rather than the knowledge that underpins it and she concludes, "an emphasis on skill precludes serious engagement by those involved in vocational education qualifications with questions of knowledge, why knowledge may be important, and how it may best be learned. The 2011 Wolf review in England has not resolved these underlying issues" (pg.17). It can also be argued that the two most recent publications on vocational pedagogy also fail to resolve the issue of knowledge within vocational subjects.

\section{The Subject or Discipline}

A glance at most of the subjects that are vocational orientated, Health and Social Care, Sports Science, Hairdressing, Construction and Engineering all have science and Maths as fundamental to their curriculum. If we define science and Maths simply as 'theoretical knowledge' it can be argued that Bathmaker's comment that "Theoretical knowledge is perceived as alien and difficult, and associated with the disengagement of 'vocational' students from formal education" (pg.92) is a pertinent one. The response by qualification makers in her research was one of "avoiding or reducing the amount of theoretical knowledge taught, rather than finding alternative ways to make it accessible" and that "the theoretical knowledge is something "we get out of the way as quickly as possible' in designing qualifications" (pg. 100). Bathmaker rightly notes the debate about skill rather than knowledge and uses Bernstein's concepts of vertical and horizontal knowledge to show how some authors advocate the need to access theoretical knowledge as a bridge in vocational education. Wheelehan (2007) also draws on Bernstein and argues that "The purpose of an academic curriculum is to induct students into a field of knowledge while the purpose of a vocational curriculum is to induct students into a field of practice" (pg.2). She argues that by using Bernstein's concept of vertical knowledge as "specialised symbolic structures of explicit knowledge" (Bernstein, 2000, pg.160), does not allow for the vocational learner to access this disciplinary knowledge within a work context. It is therefore the context of the vocational subject that is an important factor in a discussion about vocational pedagogy.

\section{The Context}

Lucas et al (2012) talk about the importance of context within vocational education and devote a chapter to the importance about the place context plays in learning. It notes the importance of 'Expanded learning' and 'Recontextualisation' (Guile, 1998) as importance facets of context and the transference of knowledge between the two. This is posed as a challenge that ensures "what is learnt in one context is applied effectively in another" (pg. 90). Later work by Guile (2006) also uses Bernstein to distinguish between vertical and horizontal knowledge and the need for "new pedagogic strategies that go beyond an emphasis on participation in practice" (pg. 259). Drawing on philosophers and psychologists for further meaning into what constitutes knowledge, Guile points out, that although the boundaries between vertical and horizontal are 'permeable' and that vertical and horizontal knowledge might 'nest' in one another, it requires the notion of 'conceptual restructuring' as learners begin to "construct an understanding of theoretical concepts based upon the foundation provided by our existing every day or theoretical concepts" (pg. 263). Guile then argues that 'conceptual restructuring' can allow us to see that knowledge cannot be separated into 'contexts' but that they are related to each other dialectically. He suggests that this has implications for vocational pedagogy with a shift in the way that the relationships between theory and practice are viewed. Wheelehan (2007) implies that within the vocational context, "Workers need to be able to transcend specific contexts and use decontextualised theoretical knowledge in different ways and in different contexts as their work grows in complexity and difficulty" (pg.2), clearly complex ideas with no clear 'ways of doing'. The following example is used to show the importance of pedagogy and subject knowledge as one way of conceptualising the part that knowledge plays in pedagogical practice.

\section{Reframing the Two or Pedagogy in Practice}

The following case study is used to highlight the importance of the 'subject' in the process of pedagogy and is presented as evidence for the importance of the need for 'disciplines' within teaching. Banks et al (1999) present two case studies that demonstrate the intricacies of learning about teaching; one through the role of mentor and the other through the notion of communities of practice. The case studies include trainees at different stages of their teaching development and Banks et al present scenarios in which the trainee's personal constructs of subject are of vital importance. The first case study involved two very new trainees who came from a background of working in technology into teaching and who had personal views of how they thought students should learn about technological issues, this being very hands-on and practical. The other case study involved a more experienced trainee who had entered teaching from an academic background in English. Whilst it is not stated that she had a degree in English, it is implied, as she is teaching 'A' Level students [Lucy] (Banks, Leach and Moon, 1999)

The case studies are presented as showing the importance of communities of practice and the role of a mentor in the 
development of successful pedagogical practice but it could be argued that they do fail to pick up on the different backgrounds of the trainees as presented in the case studies. What is clear is that the pupils of the technology trainees "became confused and then bored" (Banks et al, 1999, pg.100). Clearly the pedagogic process involved here had been flawed, but what is not commented on is the fact that, whilst teaching science, the trainees had no in depth disciplinary knowledge of that subject. It was this lack of knowledge that could have been the reason why the lesson failed to engage the students, rather than the inexperienced mentor and lack of "productive access to participation" (1999, pg.107) as Banks et al suggest. Lucy, according to Banks et al, on the other hand, has an excellent working environment, a supportive community of experienced teachers, but she also has access to a vast bank of personal 'discipline-based knowledge' that together with the other, very important factors, result in a dynamic, informative and interactive pedagogical practice, that even the experienced mentor learns from.

To provide support from literature for this perspective, Young and Gamble (2006) can be drawn on to conceptualise the complex process of pedagogy with a notion of 'dual recontextualistion' and 'boundary crossing' which is important within vocational programmes. The problematic place of the disciplines is a pertinent one and is highlighted by these case studies that show variable aspects of vocational and academic knowledge. In the case of Lucy, according to Banks et al, she had studied an academic subject whilst the other two trainees had come from a vocational background in technology. Their various successes at teaching practice could be an indicator of their different grounding in disciplinary vertical discourse and hence their knowledge about the specific subjects being taught. Lucy, with an academic grounding was able to pedagogically recontextualise the subject more successfully whilst the two technologists were unable to boundary cross into a vertical discourse and to draw upon disciplinary subject knowledge in order to restructure it for others. Lucy was able to 'face both ways', whilst the technology trainees were only able to draw on experience and not a vertical discourse in the form of academic science. It is this notion of 'facing both ways' that is the important concept here. In relation to vocational education, Bathmaker (2013) is suggesting that the practical element of vocational training is the dominant one where qualifications are concerned. It could be argued that Lucas et al (2012) also dumb down the theoretical aspects of knowledge with no real argument provided to the place of subject in the teaching of vocational education, rather an emphasis on the teaching methods that are best employed to teach all subjects. Support from an international perspective comes from Wheelahan (2007) where she notes that where training arises from a competency-based training (CBT), students lack systematic access to disciplinary knowledge. She argues that there is a process of 'delocation' of knowledge from the disciplinary frameworks that give knowledge its meaning by tying knowledge to workplace processes and tasks through an objective based curriculum. She draws on Barnett's (2006) notion of 'facing both ways' from the workplace to disciplinary knowledge and vice versa. Unless training material does this, she argues that students are not able to "recognise, identify and use the general and principled to understand the particular in a range of contexts" (pg.7). The importance of context becomes less important without the support of the subject or disciplinary knowledge.

\section{Conclusion}

It is contended that what should inform the research into vocational pedagogies next should be less about the teaching methods, the importance of contexts and the notion of 'flipped classrooms' and the 'line to work' but rather the importance of the way that science and maths, or theoretical knowledge is framed and classified within the vocational subjects. Both Bathmaker (2013) and Wheelehan (2007) go some way to discussing this with their analysis of qualifications for vocational subjects. In the past science was traditionally taught separately and remotely from the vocational subjects, recently curriculums have been diluted in terms of content of theory and more emphasis given to a task based approach. As Bathmaker points out "specialist theoretical knowledge is understood in this study as an important part of work-related vocational education and associated qualifications" (pg.101). However a return to the separatist approach would simply return the wheel, rather the research should draw on Lucas et al (2012) with their excellent proposals for the practicalities of teaching methodologies within vocational education, to a framework of rethinking the teaching of theoretical knowledge or recontextualisation and the implications of context that this brings. Interestingly Bathmaker also notes that whilst the roles of employers are vital to playing a central role in designing vocational education qualifications, there was considerable ambiguity with regard to curriculum design. Could this be that the contexts of the vocational education are so diverse that a unanimous decision about curriculum content is not possible given the contexts of engineering, health and social care and hairdressing? A 'clear line of sight' and 'It's all about work' as advocated in CAVTL seems problematic given this diversity. More importantly should be the consideration as both Bathmaker and Wheelahan observe, that by disengaging vocational learners from relevant disciplinary knowledge is a form of disempowerment and questions of equity and social justice. A consideration about the way that science itself, 'vertical knowledge' is taught and recontextualised is an important consideration that recent documents fail to address.

\section{References}


Banks, F., Leach, J., \& Moon, B. (1999). New understandings of teachers' pedagogic knowledge, in Leach, J. and Moon, B. (eds) Learners and pedagogy. The Open University.

Barnett, M. (2006). Vocational knowledge and vocational pedagogy, in Young, and Gamble, J. (Ed.), Knowledge, Curriculum and Qualifications for South African Further Education, Cape Town: Human Sciences Research Council (HSRC).

Bathmaker, A. (2013). Defining 'knowledge' in vocational education qualifications in England: an analysis of key stakeholders and their constructions of knowledge, purposes and content. Journal of Vocational Education and Training, 65, (1), 87-107. http://dx.doi.org/10.1080/13636820.2012.755210

Bernstein, B. (2000). Pedagogy, symbolic control and identity, ( $2^{\text {nd }}$ ed), Oxford: Rowman \& Littlefield Publishers.

Commission on Adult Vocational Teaching and Learning (CAVTL), (2013). It's about work. Excellent adult vocational teaching and learning. Learning and Skills Improvement Service.

Guile, D. (2006). Learning across contexts. Educational Philosophy and Theory, 38(3), 251-268. http://dx.doi.org/10.1111/j.1469-5812.2006.00193.x

Hager, P. (2004). The competence affair, or why vocational education and training urgently needs a new understanding of learning. Journal of Vocational Education \& Training, 56(3), 409-433. http://dx.doi.org/10.1080/13636820400200262

Hodgson, A., \& Spours, K. (2004). Reforming 14-19 learning: towards a new comprehensive phase of education, New Economy, 11(4), 217-223. http://dx.doi.org/10.1111/j.1468-0041.2004.00369.x

Lucas, B., Spencer, E., \& Claxton, G. (2012). How to teach vocational education: A theory of vocational pedagogy. Centre for Real-world Learning

Moodie, G. (2002). Identifying vocational education and training, Journal of Vocational Education \& Training, 54(2), 249-266. http://dx.doi.org/10.1080/13636820200200197

Pring, R. (1995). Closing the gap. Liberal education and vocational preparation. London: Hodder and Stoughton.

Polesel, J. (2001). Vocational education and training in schools in Victoria: An appraisal six years down the track, Journal of Vocational Education \& Training, 53(2), 325-340. http://dx.doi.org/10.1080/13636820100200162

Wheelahan, L. (2007). Beyond the Contextual: The importance of theoretical knowledge in vocational qualifications and the implications for work. 4th International Conference, Centre for Research in Lifelong Learning, 'The Times they are a-changin - researching transitions in lifelong learning' http://hdl.handle.net/10072/18718

Wolf, A. (2011). Review of vocational education. London: Department of Education.

\section{(cc) $\mathrm{BY}$}

This work is licensed under a Creative Commons Attribution 3.0 License. 